\title{
Bina içi iklim koşullarında verniklenmiş bazı ağaç türü odunları rutubet miktarının değişimi
}

\author{
Variation of moisture content of some varnished woods in indoor climatic conditions
}

\author{
Kemal ÜÇÜNCÜ, Aytaç AYDIN, Abdulkadir MALKOÇOĞLU, Nurgül AY
}

Karadeniz Teknik Üniversitesi, Orman Fakültesi, Orman Endüstri Mühendisliği Bölümü, Trabzon, Türkiye

\section{Eser Bilgisi / Article Info}

Araştırma makalesi / Research article DOI: 10.17474/artvinofd.315555

Sorumlu yazar / Corresponding author Kemal ÜçÜNCÜ

e-mail: : kucuncu@ktu.edu.tr

ORCID: 0000000262946112

Geliş tarihi / Received

23.05.2017

Düzeltme tarihi / Received in revised form 16.08.2017

Elektronik erişim / Online available

27.09.2017

\section{Anahtar kelimeler:}

Bina içi iklim koşulları

Odun

Odun rutubeti

Vernikleme

\section{Keywords:}

Indoor climatic conditions

Wood

Wood moisture content

Varnishing

\begin{abstract}
Özet
Bu araştırmada, verniklenmiş Karakavak (Populus nigra) ve Sarıçam (Pinus silvestris L.) ağaç türü odunlarının Trabzon'da (Türkiye) merkezi ısıtma uygulanan bina içi iklim koşullarında rutubet değişimi incelenmiştir. Bu amaçla; Karadeniz Teknik Üniversitesi Kanuni yerleşkesinde yetiştirilen her iki ağaç türü odunlarından uzunlukları $300 \mathrm{~mm}$, enine kesitleri $12.5 \mathrm{~mm}$ ve $25 \mathrm{~mm}$ teğet ve radyal, $25 \mathrm{~mm}$ ve $50 \mathrm{~mm}$ kare kesitli olmak üzere odun örnekleri elde edilmiştir. Araştırmada ayrıca verniklenmemiş referans odun örnekleri kullanılmıştır. Odun rutubeti tartı metodu, odun denge rutubeti HailwoodHorrobin modeli ve bina içi iklim koşullarında havanın bağıl nemi nemli hava termodinamiği bağıntıları ile belirlenmiştir. Sonuç olarak; verniklenmiş odun örneklerinin rutubeti ile denge rutubeti, sıcaklık ve bağıl nem arasında kuvvetli ilişkilerin olduğu görülmüştür. Aynı iklim koşullarında, verniklenmiş odunların rutubeti verniklenmemiş odunların rutubetinden yüksek bulunmuştur. Aylık rutubet ortalamaları arasındaki fark, verniklenmiş odunlarda verniklenmemiş odunlara oranla daha düşük çıkmıştır. Bu sonuçlara göre; odunun kurutulmasında belirlenecek sonuç rutubetinin, odun denge rutubetine oranla daha yüksek seçilmesinin uygun olacağı belirtilebilir. Böyle bir uygulama, aynı zamanda kurutma giderlerini de azaltacaktır. Ayrıca, verniklenmiş odunlarda rutubet değişim aralığının düşük olması çalışmayı azaltıcı yönde etkileyeceğinden, çeşitli uygulamalarda odunun verniklenerek kullanılması gerekliliği önerilebilir.
\end{abstract}

\begin{abstract}
In this study, moisture change of varnished wood of black poplar (Populus nigra) and yellow pine (Pinus silvestris L.) used in indoor climate conditions with central heating in Trabzon (Turkey) were investigated. $300 \mathrm{~mm}$ length wood specimens, with cross section of $12.5 \mathrm{~mm}$ in tangential and in radial and with the square sections of $25 \mathrm{~mm}$ and $50 \mathrm{~mm}$, were obtained from two species grown in Kanuni Campus of the Karadeniz Technical University. In this research, un-varnished wood samples were also used for reference. The wood moisture content was determined by the weighing method, the wood equilibrium moisture content by the Hailwood-Horrobin equation, and the relative humidity in the indoor climatic conditions by humid air thermodynamic principles. As a result; it was observed that the moisture content of varnished wood samples has a strong relationship with equilibrium moisture content, temperature and relative humidity. It was found that the moisture content of varnished woods was higher than the moisture content of un-varnished woods in the same climatic conditions. It was observed that the difference between the monthly average moisture content was lower in varnished woods in proportion to un-varnished woods. According to these results, it can be indicated that it would be more appropriate to select higher moisture content in the drying of wood than the equilibrium moisture content. Such an application would also reduce drying costs. Further, it can be recommended to use varnished wood in various applications because the low change range of average moisture content can affect the swelling or shrinking of wood.
\end{abstract}

\section{GiRiş}

Odunun kullanım yerindeki iklim koşullarına bağlı olarak ulaşacağı rutubet miktarının bilinmesi ve bu rutubet derecesine uygun gelen bir rutubet miktarına kadar kurutulmasının önemi bilinmekte ve birçok ülkede çeşitli kullanım yerleri için odundaki rutubet değişimleri araştırılmaktadır. Bu araştırmaların bir kısmında odun rutubeti değişimleri tartı metoduyla deneysel olarak, bir kısmında ise meteoroloji istasyonları tarafından belirlenen ortalama sıcaklık ve bağıl nem verilerinin fonksiyonu olarak belirlenmiştir.

Odunda rutubet değişiminin azaltılması ve boyutsal kararlığın sağlanması amacıyla uygulanan koruyucu yöntemlerden birisi de, yüzeysel katman oluşturan vernikleme işlemidir. Vernik; reçine esaslı saydam bir yapıda olup, ahşabın doğal ve dekoratif görünümünü kapatmayan; yağmur, güneş, mantar, küf, atmosfer koşulları, darbe, aşınma gibi etkilere karşı ahşabı koruyan bir malzemedir. Vernikler; selülozik, sentetik, poliüretan, 
polyester ve akrilik reçine esaslı, su ve çeşitli solvent bazlı birçok farklı tiplerdedir (Bulian ve Graystone 2009; Kurtoğlu 2000; Malkoçoğlu 2005).

Feist ve ark. (1985), odunun kaplanması ile rutubet değişiminin kat sayısına, alt tabaka türüne, örnek boyutuna ve maruz kalma zamanına bağlı olduğunu ifade etmiştir. Benzer şekilde, Gupta ve ark. (2016), katman kalınlığının önemini ortaya koymuştur. Sönmez ve ark. (2009), yapışma mukavemetinin \%8 odun rutubeti miktarının altında başarılı olduğunu açıklamışlardır.

Bu kapsamda Ulusal ve Uluslararası birçok çalışma yapılmıştır. Türkiye'de bina içerisinde iklim koşullarının farklı olduğu yerlerde odun rutubeti değişimleri incelenmiştir (Kantay 1976). Değişik iklim bölgelerini temsilen 8 ayrı ilde farklı kalınlıklarda Kayın, Meşe, Ladin, Göknar ve Çam kerestelerinin ısıtılan bina içerisinde ve korunaklı açık hava koşullarındaki odun denge rutubeti 2 yıl boyunca izlenmiştir (Topçuoğlu 1986). Kurtoğlu (1984), dış hava koşulları için İstanbul'da odun denge rutubeti değişimlerini deneysel olarak belirlemiş, Türkiye'nin farklı iklim yöreleri için dış iklim koşullarında odun denge rutubeti değerlerine ilişkin haritalar hazırlamıştır.

Karadeniz Bölgesinde (Türkiye) Isıtılan bina içi iklim koşullarında kullanılan ağaç malzemede oluşabilecek muhtemel odun rutubeti miktarı meteoroloji iklim verileri yardımıyla teorik olarak belirlenmiş ve yıllık değişimi verilmiştir. Ortalama iklim verilerine göre odun rutubetinin yıl boyunca $\% 6.3$ ile $\% 14.3$ arasında değişebileceği belirlenmiştir (Üçüncü 2005). Benzer şekilde, Trabzon'da kaloriferle ısıtılan bina içinde sıcaklık ve bağıl nem değişimi deneysel olarak incelenmiş ve uzun yıllar ortalamaları ile karşılaştırılmıştır (Üçüncü 1997). Trabzon'da ısıtılan bina içinde yapılan denemelerde teğet ve radyal kesitli odun örneklerinin rutubet miktarı yıl boyunca belirlenerek, odun rutubeti üzerine iklim koşullarının ve odun özelliklerinin etkileri incelenmiş ve Türkiye'de bina içi iklim koşullarında odunun ulaşabileceği muhtemel odun rutubeti miktarları verilmiştir (Üçüncü 1998; Üçüncü 2000).

Dünyada bina içi iklim koşullarında odun rutubeti, bazı çalışmalarda tartı yöntemiyle (Dittrich 1969; Kollmann 1965), bazı çalışmalarda meteorolojik verilerden yararlanılarak (Millet 1966; Tsoumis 1960; Dosthoseini 1986; Koponen 1985; Avramidis 1989) ve bazı çalışmalarda ise meteorolojik verilere, önceki araştırmalara ve yapılan gözlemlere dayanılarak (Dimitrov 1992; Tsoumis 1955; Tsoumis 1964; Ahmet ve ark. 1999; Enayati ve Hosseinabadi 2010) belirlenmiştir.

Kolombiya'da tahtaların uzun süre depolanması için çevre koşullarının optimizasyonu yapılmıştır. Bu amaçla çeşitli sıcaklık ve bağıl nem kademelerinde odun denge rutubeti değerleri belirlenmiş olup; sıcaklık, bağıl nem ve denge rutubeti arasındaki ilişkiler için lineer regresyon analizlerine dayalı denklemler elde edilmiştir (Macias ve ark. 1990).

Vital ve ark. (1982) Okaliptus saligna odun örneklerinde sıcaklığın odunun higroskopisitesi ve stabilitesi üzerindeki etkilerini araştırmıştır. Araştırma sonucu, sürenin ve sıcaklığın artması halinde odun denge rutubetinin azaldığını göstermiştir. Majka ve ark. (2014) tarafından yapılan araştırmada, kurutma sıcaklığının histerez üzerinde düşük düzeyli de olsa bir etkiye sahip olduğunu açıklamışlardır. Simpson (1998), Hailwood ve Horrobin (1946) tarafından geliştirilen adsorpsiyon modelini kullanarak $A B D$ 'de ve dünya çapında bazı şehirler için açık hava koşullarında odun denge rutubeti miktarlarını belirlemiştir.

Newby ve Brennan (1990) farklı çevre koşulları etkisinde Jarrah ve Karri odunlarının 300 mm x 100 mm x 30 mm boyutlarındaki örneklerinde rutubet değişimlerini incelemiş ve özellikle mobilya üretiminde kullanılacak kerestenin son kullanım yeri için gerekli rutubet miktarına kadar kurutulması gerektiğini belirterek, üretilen mobilyaların tamamen PVC ile kaplanmasını önermişlerdir.

Bu araştırmada, Trabzon'da (Türkiye) bina içi iklim koşullarında verniklenmiş Karakavak (Populus nigra) ve Sarıçam (Pinus silvetris L.) ağaç türü odunlarının rutubet değişimi deneysel olarak incelenmiş ve uzun yıllar ortalama iklim verilerine göre aylık odun rutubeti ortalamaları belirlenmiştir. Ayrıca, verniklenmiş odun örneklerinin rutubet değişimi, referans olarak kullanılan verniklenmemiş odun örneklerinin rutubet değişimi ile karşılaştırılmıştır. 


\section{MATERYAL ve YÖNTEM}

\section{Materyal}

Araştırmada, Karadeniz Teknik Üniversitesi Kanuni yerleşkesinde yetişen Karakavak (Populus nigra) ve Sarıçam (Pinus sylvestris L.) odun örnekleri kullanılmıştır. Örnek seçimi TS 2470 (1976), rutubet miktarı tayini TS 2471 (1976) ve birim hacim ağırlığı (yoğunluk) tayini TS 2472 (1976)'ye göre yapılmıştır. Karakavak odun örneklerinin tam kuru yoğunluğu $0.380 \mathrm{gcm}-3$, Sarıçam odun örneklerinin tam kuru yoğunluğu $0.376 \mathrm{gcm}-3$ olarak belirlenmiştir.

Ağaç türlerinin her birinden üçer adet $100 \mathrm{~cm}$ 'lik kısımları denemelerde örnek materyali olarak alınmıştır. Her kısımdan 2'şer adet olmak üzere 6 adet örnek ve her ağaç türünden toplam 36'şar adet örnek hazırlanmıştır. Odun örneklerinin örnek planı Çizelge 1'de verilmiş, gövde odunundan alınış şekli ve enine kesitleri şekil 1'de gösterilmiştir.

\begin{tabular}{|c|c|c|c|c|c|}
\hline $\begin{array}{l}\text { Örnek } \\
\text { tipi }\end{array}$ & $\begin{array}{l}\text { Kalınlık } \\
(\mathrm{mm})\end{array}$ & $\begin{array}{l}\text { Genişlik } \\
(\mathrm{mm})\end{array}$ & $\begin{array}{l}\text { Uzunluk } \\
(\mathrm{mm})\end{array}$ & Kesit & $\begin{array}{l}\text { Örnek } \\
\text { sayısı }\end{array}$ \\
\hline T12.5 & 12.5 & 100 & 300 & Teğet & 6 \\
\hline R12.5 & 12.5 & 100 & 300 & Radyal & 6 \\
\hline T25 & 25 & 100 & 300 & Teğet & 6 \\
\hline R25 & 25 & 100 & 300 & Radyal & 6 \\
\hline K25 & 25 & 25 & 300 & Kare & 6 \\
\hline K50 & 50 & 50 & 300 & Kare & 6 \\
\hline
\end{tabular}

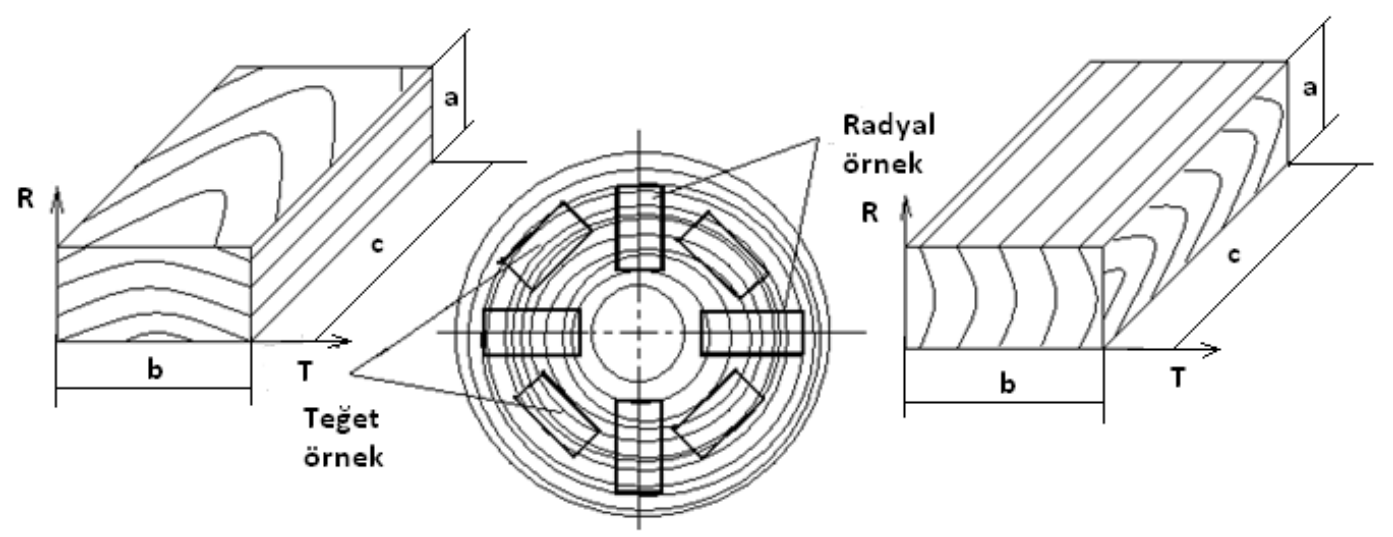

Şekil 1. Teğet ve radyal kesitli odun örnekleri kesim planı

$\mathrm{Bu}$ araştırmada, odun örnekleri belirli bir süre denemelerin yapılacağı ortamda denge rutubetine ulaşıncaya kadar bekletilmiş ve kalınlık makinasında işlendikten sonra zımparalanmıştır (Bulian ve Graystone 2009; Kurtoğlu 2000; Malkoçoğlu 2005).

Vernikleme işleminde poliüretan bileşenli vernik kullanılmış; birinci aşamada iki kat dolgu verniği (1:1), ikinci aşamada iki kat son kat verniği (3:1) vernik tabancasıyla uygulanmıştır. Vernikleme işlemi standartlara (ASTM D3023-98) ve pratik uygulamalara uygun olarak yapılmış ancak, katman kalınlığı ölçülmemiştir. Verniklenmiş odun örnekleri, denemelere başlanmadan önce ortam denge rutubetine uyum sağlamaları amacıyla ısıtılan bina içi iklim koşullarında bekletilmiştir.

\section{Yöntem}

Odun örnekleri Karadeniz Teknik Üniversitesi Lojmanlarında kaloriferle ısıtılan bir odada ortalama iklim koşullarının hâkim olduğu bir yerde bekletilerek denemeler yapılmıştır. Ölçümlerin yapıldığı odanın döşemesi ahşap olup, oda içinde ayrıca higroskopik madde bulunmamaktadır.

Isıtılan bina içindeki hava koşullarında sıcaklık ve bağıl nem termohigrografla ölçülmüş ve kaydedilmiştir. Bina içi günlük sıcaklık ve bağıl nem ortalamaları günün 7,14 ve 21. saatlerindeki ölçüm değerlerinden hesaplanmıştır (Bulut ve ark. 1999). Aylık ortalama iklim verileri günlük ortalamalardan belirlenmiştir. Dış hava koşulları Trabzon Meteoroloji istasyonu ölçümlerinden alınmıştır. Denemelerin yapıldığı yerle rasat sonuçlarının alındığı 
yerin dış iklim koşulları arasında belirgin bir fark bulunmamıştır.

Bina içinde ölçülen bağıl nem değerleri ile karşılaştırmak amacıyla bina içi bağıl nemi ayrıca teorik olarak da hesaplanmıştır. Teorik bağıl nemin hesaplanmasında (1) nolu eşitlik kullanılmıştır (Üçüncü 1997; Ayhan 1988).

$\varphi=\frac{\rho_{\mathrm{b}}}{\rho_{\mathrm{bd}}}$

Burada $\rho_{b}$ birim hacimdeki nemli hava içerisinde bulunan su buharı miktarı $\left(\mathrm{gm}^{-3}\right), \rho_{\text {bd }}$ ise birim hacimde nemli havanın toplam basınç ve sıcaklıkta taşıyabileceği su buharı miktarıdır $\left(\mathrm{gm}^{-3}\right)$.

Birim hacimdeki nemli hava içerisinde doyma durumunda bulunabilecek su buharı miktarı sıcaklığın (T) fonksiyonu olarak (2) nolu denklem yardımıyla hesaplanmıştır (Üçüncü 1996; Üçüncü 1997).

$\rho_{\mathrm{bd}}=4.84+0.3738 \mathrm{~T}+0.0044 \mathrm{~T}^{2}+0.00037 \mathrm{~T}^{3}\left[\mathrm{gcm}^{-3}\right]$

Odun esaslı malzemelerin bulunduğu ve insanların yaşadığı ısıtılan kapalı ortamda nemli hava içerisinde bulunabilecek mutlak nem miktarı (3) nolu denklem yardımıyla hesaplanmıştır (Üçüncü ve ark. 2015).

$\rho_{\mathrm{b}}=\rho_{\mathrm{b}, \mathrm{d}}+\mathrm{c}_{1} \mathrm{~W}+\mathrm{c}_{2} \mathrm{~W}_{\mathrm{s}}+\mathrm{c}_{3} \mathrm{~W}_{\mathrm{t}}\left\lceil\mathrm{g} \mathrm{m}^{-3}\right\rceil$

Burada, W odundaki rutubet değişimi miktarı, $\mathrm{W}_{\mathrm{t}}$ terleme ve $W_{s}$ soluma miktarı; $c_{1}$ odun rutubeti, $c_{2}$ soluma ve $c_{3}$ terleme sabitleridir. Denklem sabitleri, $M_{0}$ kuru odun miktarı, $M_{s}$ soluma miktarı, $M_{t}$ terleme miktarı, $V_{i}$ net mekan hacmi, $\mathrm{t}$ etkinlik süresi ve $\mathrm{n}$ hava değişim oranı olmak üzere (4), (5) ve (6) nolu eşitlikler kullanılarak bulunmuştur (Üçüncü ve ark. 2015).

$\mathrm{c}_{1}=\frac{\mathrm{M}_{\mathrm{o}}}{\mathrm{V}_{\mathrm{i}} \mathrm{tn}}$

$\mathrm{c}_{2}=\frac{\mathrm{M}_{\mathrm{s}}}{\mathrm{V}_{\mathrm{i}} \mathrm{tn}}$

$\mathrm{c}_{3}=\frac{\mathrm{M}_{\mathrm{t}}}{\mathrm{V}_{\mathrm{i}} \mathrm{tn}}$

Odun örnekleri günün belirli saatlerinde, günlük ve haftalık olarak $0.01 \mathrm{~g}$ duyarlılıktaki terazide tartılmış, denemelerin bitiminden sonra odun rutubeti kurutma yöntemi ile belirlenmiştir. Rutubetli ağırlığı $\left(M_{r}\right)$, belirlenen odun örneği kurutma dolabında sıcaklıkta tam kuru hale kadar kurutularak tam kuru ağırlığı ( $\mathrm{M}_{\mathrm{o}}$ ) ölçülmüştür. Tam kuru ağırlığı belirlenen odun örneklerinin rutubetleri (7) nolu eşitlik yardımıyla hesaplanmıştır.

$\mathrm{W}=\frac{\mathrm{M}_{\mathrm{r}}-\mathrm{M}_{\mathrm{o}}}{\mathrm{M}_{\mathrm{o}}}$

Bulunduğu iklim koşullarına (sıcaklık ve bağıl nem) göre odun denge rutubeti ayrıca Simpson (1973) tarafindan verilen, Hailwood ve Horrobin (1946) tarafından belirlenen katsayıların kullanıldığı eşitliği ile hesaplanmıştır.

$\mathrm{DRM}=\frac{1800}{\mathrm{~W}}\left[\frac{\mathrm{KH}}{1-\mathrm{KH}}+\frac{\mathrm{K}_{1} \mathrm{KH}+2 \mathrm{~K}_{1} \mathrm{~K}_{2} \mathrm{~K}^{2} \mathrm{H}^{2}}{1+\mathrm{K}_{1} \mathrm{KH}+\mathrm{K}_{1} \mathrm{~K}_{2} \mathrm{~K}^{2} \mathrm{H}^{2}}\right]$

$\mathrm{W}=349+1.29 \mathrm{~T}+0.0135 \mathrm{~T}^{2}$

$\mathrm{K}=0.805+0.000736 \mathrm{~T}-0.00000273 \mathrm{~T}^{2}$

$\mathrm{K}_{1}=6.27-0.0398 \mathrm{~T}-0.000303 \mathrm{~T}^{2}$

$\mathrm{K}_{2}=1.91+0.0407 \mathrm{~T}-0.000293 \mathrm{~T}^{2}$

Burada; DRM odun denge rutubeti (\%), $\mathrm{H}$ bağıl nem (\%/100) ve W, K, K 1 ve $K_{2}$ Hailwood ve Horrobin (1946) tarafından geliştirilmiş adsorpsiyon modeli katsayıları, $\mathrm{T}$ sıcaklık $\left({ }^{\circ} \mathrm{C}\right)$ olarak belirtilmişitir.

Odun kalınlığı, enine kesit ve odun türleri arasındaki farklarla; odun rutubeti, sıcaklık, bağıl nem ve odun denge rutubeti arasındaki ilişkilerin belirlenmesi için SPSS23 istatistik paket programı kullanılmıştır.

Odun rutubeti ile sıcaklık, bağıl nem ve HailwoodHorrobin modeli ile belirlenen odun denge rutubeti arasındaki ilişkilerin belirlenmesi amacı ile regresyon analizleri yapılmıştır. Denemelerle belirlenen regresyon eşitliklerinden yararlanılarak Trabzon'da ısıtılan bina içi uzun yıllar iklim koşulları için aylık odun rutubeti ortalamaları hesaplanmıştır. Hesaplarda kullanılan dış hava koşullarına ilişkin veriler Meteoroloji Genel Müdürlüğü Trabzon rasat verilerinden elde alınmıştır (DMGM 2015). Uzun yıllar için yapılan hesaplamalarda, 
ısıtma döneminde bina içi sıcaklığın $20^{\circ} \mathrm{C}$ 'de sabit tutulduğu varsayılmıştır (MMO 2010).

\section{BULGULAR}

Vernikli Karakavak ve Sarıçam ağaç türü odun örnekleri ısıtma döneminde denemelerin yapılacağı bina içinde bir süre bekletilerek denge rutubetine ulaşması sağlanmıştır. Deneyler, ısıtılan ve ısıtılmayan dönemde olmak üzere iki aşamada gerçekleştirilmiştir. Karakavak ve Sarıçam odun örneklerinde oluşan deneysel rutubet miktarları Çizelge 2 ve Çizelge 3'de verilmiştir. Deney döneminde odun örneklerinin ortalama rutubeti Karakavak'ta \%11.8, Sarıçam'da \%12.1 olarak belirlenmiştir.

Çizelge 2. Verniklenmiş Karakavak odunu örnekleri deneysel günlük ortalama odun rutubeti istatistiksel dağılımı

\begin{tabular}{|c|c|c|c|c|c|c|c|c|}
\hline \multirow[t]{2}{*}{ Karakavak Örnekler } & \multirow[t]{2}{*}{$\mathbf{N}$} & \multirow[t]{2}{*}{ Ortalama } & \multirow[t]{2}{*}{ Std. Sapma } & \multirow[t]{2}{*}{ Std. Hata } & \multicolumn{2}{|c|}{ Ortalama için\% 95 güven aralığı } & \multirow[t]{2}{*}{ Min. } & \multirow[t]{2}{*}{ Max. } \\
\hline & & & & & Alt sınır & Üst sınır & & \\
\hline $1(\mathrm{~T} 12.5)$ & 60 & 11.7400 & 3.71950 & 0.48018 & 10.7792 & 12.7008 & 7.80 & 18.00 \\
\hline 2 (R12.5) & 60 & 11.7483 & 3.69294 & 0.47676 & 10.7943 & 12.7023 & 7.80 & 18.00 \\
\hline $3(\mathrm{~T} 25)$ & 60 & 11.8933 & 3.71560 & 0.47968 & 10.9335 & 12.8532 & 7.80 & 18.00 \\
\hline $4(\mathrm{R} 25)$ & 60 & 11.8317 & 3.74838 & 0.48391 & 10.8634 & 12.8000 & 7.70 & 18.10 \\
\hline $5(25 \times 25)$ & 60 & 11.8917 & 3.77643 & 0.48754 & 10.9161 & 12.8672 & 7.70 & 18.50 \\
\hline $6(50 \times 50)$ & 60 & 11.9667 & 3.78958 & 0.48923 & 10.9877 & 12.9456 & 7.80 & 18.30 \\
\hline Total & 360 & 11.8453 & 3.71532 & 0.19581 & 11.4602 & 12.2304 & 7.70 & 18.50 \\
\hline
\end{tabular}

Çizelge 3. Verniklenmiş Sarıçam odunu örnekleri deneysel günlük ortalama odun rutubeti istatistiksel dağılımı

\begin{tabular}{|c|c|c|c|c|c|c|c|c|}
\hline \multirow[t]{2}{*}{ Sarıçam Örnekler } & \multirow[t]{2}{*}{$\mathbf{N}$} & \multirow[t]{2}{*}{ Ortalama } & \multirow[t]{2}{*}{ Std. Sapma } & \multirow[t]{2}{*}{ Std. Hata } & \multicolumn{2}{|c|}{ Ortalama için\% 95 güven aralığı } & \multirow[t]{2}{*}{ Min. } & \multirow[t]{2}{*}{ Max. } \\
\hline & & & & & Alt sınır & Üst sınır & & \\
\hline 1 (T12.5) & 60 & 12.1100 & 3.81787 & 0.49289 & 11.1237 & 13.0963 & 8.00 & 18.70 \\
\hline 2 (R12.5) & 60 & 12.0650 & 3.74907 & 0.48400 & 11.0965 & 13.0335 & 8.10 & 18.70 \\
\hline $3(\mathrm{~T} 25)$ & 60 & 12.0883 & 3.87181 & 0.49985 & 11.0881 & 13.0885 & 7.60 & 18.40 \\
\hline $4(\mathrm{R} 25)$ & 60 & 12.0600 & 3.84356 & 0.49620 & 11.0671 & 13.0529 & 7.80 & 18.50 \\
\hline $5(25 \times 25)$ & 60 & 12.0583 & 3.85030 & 0.49707 & 11.0637 & 13.0530 & 7.80 & 18.30 \\
\hline $6(50 \times 50)$ & 60 & 12.1183 & 3.81582 & 0.49262 & 11.1326 & 13.1041 & 7.90 & 18.20 \\
\hline Total & 360 & 12.0833 & 3.79828 & 0.20019 & 11.6896 & 12.4770 & 7.60 & 18.70 \\
\hline
\end{tabular}

Enine kesit, kalınlık ve ağaç türünün odun rutubeti üzerindeki etkilerini belirlemek için yapılan varyans analizi sonuçları Çizelge 4’de verilmiştir. Görüleceği gibi; ağaç türü, kalınlık ve kesit faktörlerinin odun rutubeti üzerinde \%5 yanılma olasılığı ile istatistiksel olarak anlamlı bir etkisi olmamıştır ( $p>0.05)$.

Araştırma dönemine ilişkin vernikli ve verniklenmemiş odun rutubeti aylık deneysel ortalamalarının değişimi Şekil 2' de gösterilmiştir.

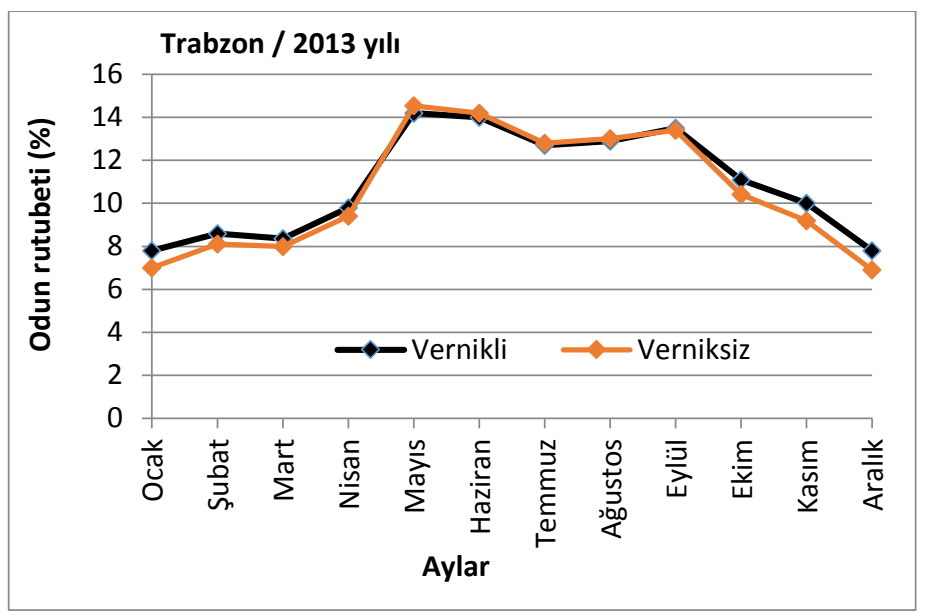

Şekil 2. Odun rutubetinin aylık değişimi (2013) 
Çizelge 4. Odun rutubeti varyans analizi sonuçları

\begin{tabular}{|c|c|c|c|c|c|}
\hline Özelik 1 & Özelik 2 & Faktör 1 & Faktör 2 & $\mathbf{F}$ & $\mathbf{p}$ \\
\hline \multirow{4}{*}{ Karakavak } & $12.5 \mathrm{~mm}$ & Teğet & Radyal & 0.019 & 0.892 \\
\hline & $25 \mathrm{~mm}$ & Teğet & Radyal & 0.027 & 0.870 \\
\hline & Kare & $25 \mathrm{~mm} \times 25 \mathrm{~mm}$ & $50 \mathrm{~mm} \times 50 \mathrm{~mm}$ & 0.321 & 0.572 \\
\hline & Kalınlık & $12.5 \mathrm{~mm}$ & $25 \mathrm{~mm}$ & 0.059 & 0.809 \\
\hline \multirow{4}{*}{ Sarıçam } & $12.5 \mathrm{~mm}$ & Teğet & Radyal & 0.017 & 0.895 \\
\hline & $25 \mathrm{~mm}$ & Teğet & Radyal & 0.047 & 0.828 \\
\hline & Kare & $25 \mathrm{~mm} \times 25 \mathrm{~mm}$ & $50 \mathrm{~mm} \times 50 \mathrm{~mm}$ & 0.370 & 0.544 \\
\hline & Kalınlık & $12.5 \mathrm{~mm}$ & $25 \mathrm{~mm}$ & 0.042 & 0.839 \\
\hline Ağaç türü & & Karakavak & Sarıçam & 0.260 & 0.611 \\
\hline \multirow{4}{*}{ Genel } & $12.5 \mathrm{~mm}$ & Teğet & Radyal & 0.024 & 0.876 \\
\hline & $25 \mathrm{~mm}$ & Teğet & Radyal & 0.037 & 0.848 \\
\hline & Kare & $25 \mathrm{~mm} \times 25 \mathrm{~mm}$ & $50 \mathrm{~mm} \times 50 \mathrm{~mm}$ & 0.351 & 0.554 \\
\hline & Kalınlık & $12.5 \mathrm{~mm}$ & $25 \mathrm{~mm}$ & 0.035 & 0.852 \\
\hline
\end{tabular}

Karakavak ve Sarıçam ağaç türü odunlarının rutubetleri arasında \% 95 güven düzeyinde farklılığın olmadığı dikkate alınarak her iki türün temsil ettiği ortalama odun rutubetinin hesaplanabileceği görülmüştür $(p=0.611)$.

Odun rutubeti aylık ortalamaları verniklenmiş ve verniklenmemiş odunlar için karşılaştırılmış ve istatistiksel dağılımları Çizelge 5'de verilmiştir. Verniklenmiş ve verniklenmemiş odun rutubeti aylık ortalamaları arasında $\% 5$ yanılma olasıı̆ı̆ı ile anlamlı farklılık bulunmamıştır ( $p=$ 0.769). Ancak, odunların yıllık ortalama rutubet değerleri, verniklenmiş odunlarda verniklenmemiş odunlara oranla $\% 0.3$ yüksek bulunmuştur.

Çizelge 5. Verniklenmiş ve verniklenmemiş deneysel odun rutubeti aylık ortalama istatistiksel dağılımı

\begin{tabular}{|c|c|c|c|c|c|c|c|c|}
\hline & \multirow[t]{2}{*}{$\mathbf{N}$} & \multirow[t]{2}{*}{ Ortalama } & \multirow[t]{2}{*}{ Std. Sapma } & \multirow[t]{2}{*}{ Std. Hata } & \multicolumn{2}{|c|}{ Ortalama için\% 95 güven aralığı } & \multirow[t]{2}{*}{ Min. } & \multirow[t]{2}{*}{ Max. } \\
\hline & & & & & Alt sınır & Üst Sınır & & \\
\hline Verniklenmiş & 12 & 10.90 & 2.47 & 0.71 & 9.33 & 12.47 & 7.80 & 14.20 \\
\hline Verniklenmemiş & 12 & 10.58 & 2.86 & 0.82 & 8.76 & 12.39 & 6.90 & 14.50 \\
\hline Total & 24 & 10.74 & 2.62 & 0.53 & 9.63 & 11.84 & 6.90 & 14.50 \\
\hline
\end{tabular}

Ortalama odun rutubetinin havanın sıcaklık ve bağı nemine aylık uyumu günlük uyumundan daha yüksek olduğu için değerlendirmelerde aylık ortalamalar kullanılmıştır. Verniklenmiş (vl) ve verniklenmemiş (vs) odun rutubeti miktarı (RM) ile sıcaklık (T) - bağıl nem (H) ve odun denge rutubeti (DRM) arasında aşağıdaki regresyon denklemleri elde edilmiştir. Bu bağıntılar, \%30 - \%80 bağıl nem aralığında Hailwood ve Horrobin modeli ile uyum sağlamaktadır.

$\mathrm{RM}_{\mathrm{vl}}=2.892+0.177 \mathrm{H}-0.080 \mathrm{~T} ; \mathrm{r}^{2}=0.991$

$\mathrm{RM}_{\mathrm{vs}}=0.451+0.204 \mathrm{H}-0.052 \mathrm{~T} ; \mathrm{r}^{2}=0.990$
$\mathrm{RM}_{\mathrm{vl}}=1.409+0.956 \mathrm{DRM} ; \mathrm{r}^{2}=0.995$

$\mathrm{RM}_{\mathrm{vs}}=-0.394+1.105 \mathrm{DRM} ; \mathrm{r}^{2}=0.997$

Deneysel eşitlikler kullanılarak Trabzon için uzun yıllar iklim verileri ortalamalarına göre (1950-2015) verniklenmiş ve verniklenmemiş odun rutubetinin aylık ortalamalar belirlenerek Çizelge 6'da verilmiş, aylık değişimleri Şekil 3'de gösterilmiştir. Verniklenmiş ve verniklenmemiş odun rutubeti aylık ortalamaları arasında \%5 yanılma olasılığı ile anlamlı farklılık bulunmamıştır ( $p=$ 0.807). 
Çizelge 6. Uzun yıllar odun rutubeti aylık ortalamaları

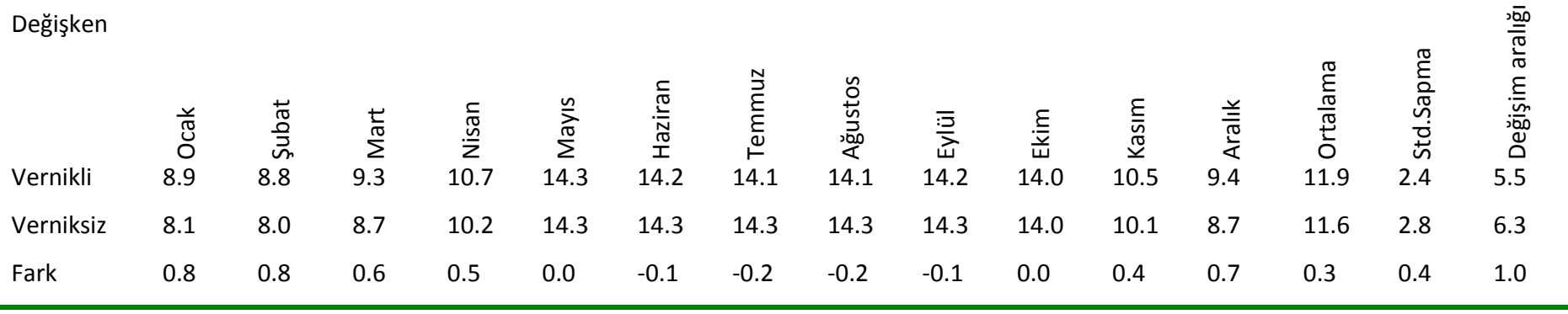

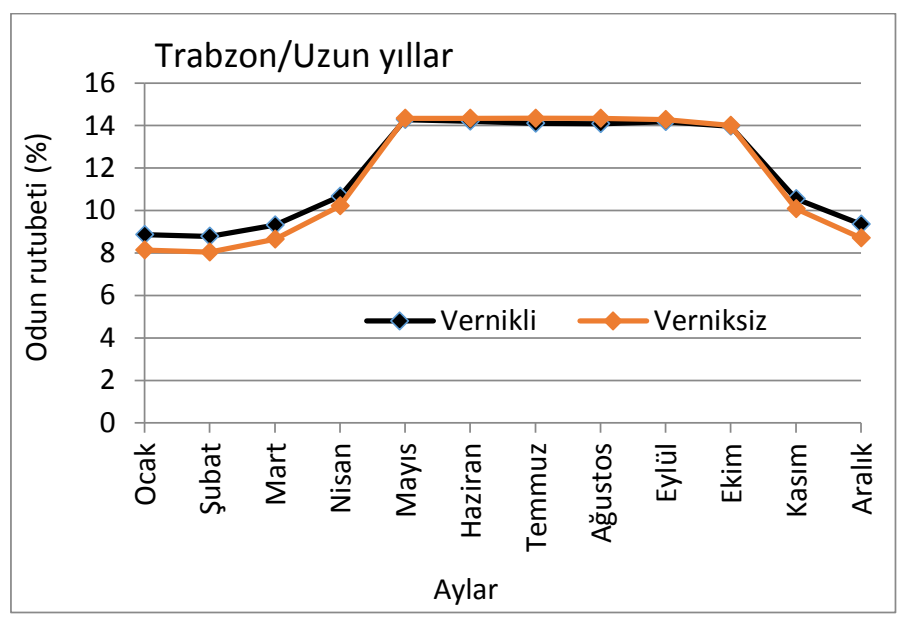

Şekil 3. Trabzon'da bina içi iklim koşullarında odun rutubeti uzun yıllar aylık ortalamaları

Verniklenmiş odunun uzun yıllar aylık ortalamaları \%8.8 (Şubat) ile \% 14.3 (Mayıs) arasında, verniklenmemiş odunun uzun yıllar aylık ortalamaları ise \%8.0 (Şubat) ile \%14.3 (Mayıs - Eylül) arasında değişmiştir. Uzun yıllar aylık odun rutubeti ortalamaları arasındaki farklılık verniklenmiş odunlar için \%5.5, verniklenmemiş odunlar için \%6.3 olarak bulunmuştur. Uzun yıllar odun rutubeti ortalaması verniklenmiş odun için $\% 11.9$, verniklenmemiş odun için \%11.6'dır. Verniklenmiş odun rutubeti ile verniklenmemiş odun rutubeti aylık ortalamaları arasındaki farklııık, ısıtma dönemi dışındaki aylarda (yaz dönemi) ısıtma dönemindeki (kış dönemi) aylara oranla daha düşük bulunmuştur.

\section{TARTIŞMA VE SONUÇ}

Ağaç türü, kalınlık ve kesitin odun rutubeti üzerindeki etkileri ile ilgili bu sonuçların literatür bulguları ile uyum sağladığı görülmüştür (Gupta ve ark. 2016; Feist ve ark. 1985; Üçüncü 2000). Bu bulgulara uygun olarak odun rutubetinin odun denge rutubeti, sıcaklık ve bağıl nem ile ilişkilerini gösteren regresyon denklemleri elde edilmiştir. Benzer bir araştırmada, Schniewind ve Arganbright (1984), kaplamaların türü ve film kalınlığının odun rutubeti değişiminde bir kararlıık sağladığını, ancak bu durumda iç gerilme riskinin oluşabileceğini ifade etmiştir.

Trabzon'da bina içi uzun yıllar iklim koşullarında regresyon denklemleri yardımıyla hesaplanan odun rutubeti yıllık ortalamaları; verniklenmiş odun için \% 11.9 , verniklenmemiş odun için ise \% 11.6 olarak belirlenmiştir. Verniklenmiş odun örneklerinin rutubeti, verniklenmemiş odun örneklerinin rutubetine göre kış aylarında yaz aylarına oranla daha yüksek bulunmuştur. Vernikli odunda rutubet miktarının verniklenmemiş oduna oranla yaz aylarında yüksek, kış aylarında düşük bulunması verniklemenin rutubet değişimi üzerindeki yavaşlatıcı etkisini doğrulamaktadır.

Odunun verniklenmiş olması, verniklenmemiş oduna göre rutubetin etki hızını önemli ölçüde yavaşlatmaktadır. Rutubet difüzyonundaki bu yavaşlama verniklenen odunun rutubetinin denge rutubetine ulaşmasını geciktirmekte ve yıllık ortalama odun denge rutubetine oranla daha yüksek değerlerde seyretmektedir.

Araştırma bulguları, odunun kurutulması için literatürde gösterilen sonuç rutubeti miktarlarına göre, verniklenerek kullanılacak odunların kurutulmasında daha yüksek sonuç rutubeti değerlerinin seçilebileceğini göstermiştir. Böyle bir uygulama, aynı zamanda kurutma giderlerinin de azalmasını sağlayacaktır. Ayrıca, verniklenmemiş odunda yıllık rutubet değişimi farkı \%6.3 iken, verniklenmiş odunda bu fark \%5.5 olmuştur. Rutubet değişim aralığının verniklenmiş odunda daha düşük olması, odunun çalışmasını azaltması bakımından 
uygulamaları olumlu yönde etkileyeceği ortaya konulabilir.

Vernikleme işleminde kaplamanın niteliği odun rutubetine (Sönmez ve ark. 2009), yüzey pürüzlülüğüne (Paic ve ark. 2014), katman kalınlığına (Gupta ve ark. 2016) ve alt tabaka türüne ve odun kalınlığına (Feist ve ark. 1985) bağlı olduğundan vernikleme koşullarının ayrı bir çalışmada değerlendirilmesi yararlı olabilir.

\section{KAYNAKLAR}

Ahmet K, Dai G, Jazayeri S, Tomlin R, Kaczmar P, Riddiough S (1999) Experimental procedures for determining the equilibrium moisture content of twenty timber species. Forest Products Journal 49 (1):88-93

ASTM.D-3023 (1998) Standard practice for determination of resistance of factory applied coatings on wood products of stain and reagents

Avramidis S (1989) Evaluation of three-variable models for the prediction of equilibrium moisture content in wood. Wood Science and Technology 23 (3):251-258

Ayhan T (1988) Nemli hava termodinamiği. Karadeniz Teknik Üniversitesi Ders Notları No: 16, Trabzon

Bulian F, Graystone JA (2009) Wood coatings, Theory and practice. Elsevier Radarweg 29, POBox 211, 1000 AE Amsterdam

Bulut H, Büyükalaca O, Yılmaz A (1999) Türkiye'nin 15 ili için bazı iklim verilerinin eşitliklerle ifadesi. TMMOB Makina Mühendisleri Odası, Tesisat Mühendisliği Dergisi 51:48-56

Dimitrov T (1992) Climate and naturel wood drying. Drvna Ind. 43(2):62-70

Dittrich H (1969) Einflüsse des aussenklimas auf die holzfeuchtigkeit von verbautem holz in innenraumen. Holz - Zentralblatt 95(8):79

DMGM (2015) Türkiye'de uzun yıllar sıcaklık ve bağıl nem aylık ortalama değerleri. Devlet Meteoroloji isşleri Genel Müdürlüğü, Ankara

Dosthoseini K (1986) Determination of equilibtium moisture content of wood at various locations in Iran. Iranian Journal of Naturel Resources 39:29-36

Enayati AA, Hosseinabadi HZ (2010) Determination of equilibrium moisture content (EMC) of wood in the neighboring Countries of Iran. International Union of Forest Research Organizations XXIII World Congress, $23-28$ August, Seoul, Korea

Feist WC, Little JK, Wennesheimer JM (1985) The moisture - excluding effectiveness of finishes on wood surfaces. Res. Pap. FPL 462 Madison, WI: U.S. Department of Agriculture, Forest Service, Forest Products Laboratory 38p

Gupta S., John A., Kumar K (2016) Studies on effect of coat thickness on the moisture uptake by a hardwood substrate. Maderas - Cienc. Tecnol. 18(3):443-456

Hailwood AJ, Horrobin S (1946) Absorption of water by poliymers: Analysis in terms of a simple model. Trans. Faraday Soc. 42B:84102
Jaic, M., Palija, T and Dordevic M (2014) The impact of surface preparation of wood on the adhesion of certain types of coatings. Zastita Materijala, 55(2): 163-169

Kantay R (1976) Bir binanın klimatik bakımdan değişik yerlerinde ağaç malzemede meydana gelen denge rutubeti değişimine ait denemeler. iü Orman Fakültesi Dergisi, Seri A. 26(2):211-217

Kollmann $F$ (1965) Freilufttrocknung und beschleunigte freilufttrocknung. Holztrocknung. Holzwirtschaftliches Jahrbuch $\mathrm{Nr}:$ 15, 51

Koponen H (1985) Sorption isotherms of finnsch birch, pine and spruce. Paperi Ja Puu., 67(2):70-72, 74-77

Kurtoğlu A (1984) Hava kurusu odunda rutubet değişmeleri ve Türkiye'de odunun muhtemel denge rutubeti miktarlarının dağıımı. iü Orman Fakültesi yayın no. 362. İstanbul

Kurtoğlu A (2000) Ağaç malzeme yüzey işlemleri: Genel bilgiler, Cilt I. iÜ Orman Fakültesi, Orman Endüstri Mühendisliği Bölümü, İstanbul

Macias EB, Garcia BHR, Galvis VJA (1990) Determination of equilibrium humidity in Panela. Agronomia Colombiana 7(1-2):70-75

Majka J, Olek W, Zofia Kudła-Chwiłowicz Z (2014) Determination of moisture content changes in kiln-dried scots pine timber during storage. Drewno 57(191):45-54

Malkoçoğlu A (2005) Yüzey işlemleri, Ders Notları (Yayımlanmamış). KTÜ Orman Fakültesi Orman Endüstri Mühendisliği Bölümü, Trabzon

Millet SR (1966) Wood seasoning, Department of Forest technical Note No:20. Ottowa, Canada

MMO (2010) Kalorifer tesisatı. Makina Mühendisleri Odası Yayın No:352, Ankara

Newby P, Brennan GK (1990) Moisture content fluctuations of regrowth jarrah anda karri under different environmental conditions. Rep. Wood Utilisation Res. Centre, No: 18, 8p

Schniewind AP and Arganbright DG (1984) Coatings and their effect on dimensional stability of wood. WAAK, 6(2):2-5

Simpson WT (1998) Equilibrium moisture content of wood in outdoor locations in the United States and worlwide. United States Departmant of Agriculture Forest Service Forest Product Laboratory

Sönmez A, Budakçı M, Bayram M (2009) Effect of wood moisture content on adhesion of varnish coatings. Scientific Research and Essay, 4(12):1432-1437

Topçuoğlu MY (1986) Türkiye'nin değişik iklim bölgelerinde denge rutubetinin saptanmasına ilişkin araştırmalar. Ormancılık Araştırma Enstitüsü Yayınları, Teknik Bülten Serisi No:159

TS 2471 (1976) Odunda, fiziksel ve mekaniksel dneyler için rutubet miktari tayini. Türk Standartları Enstitüsü, Ankara

TS 2472 (1976) Odunda, fiziksel ve mekaniksel dneyler için birim hacim ağırlığı tayini. Türk Standartları Enstitüsü, Ankara

TS2470 (1976) Odunda, fiziksel ve mekaniksel dneyler için numune alma metotları ve fenel özellikler. Türk Standartları Enstitüsü, Ankara

Tsoumis G (1955) Moisture content of wood under the climatic conditions of Greece. Technica Chronica 32(371-372):158-162 
Tsoumis G (1960) Untersuchungen über die schwankungen des feuchtigkeitsgehaltes von lufttrockenem holz. Holz als Roh - und Werkstoff Bd., 18:415-422

Tsoumis G (1964) Estimated moisture content of air - dry wood exposed to the atmosphere under shelter. Especially in Europa. Holzforschung Bd. 18:76-81

Üçüncü K (2005) Karadeniz Bölgesinde bina içi iklim koşullarında odun denge rutubeti dağıııının analizi. Kafkas Üniversitesi Artvin Orman Fakültesi Dergisi, 6(1-2):46-58.

Üçüncü K (1997) Isıtılan binalarda sıcaklık ve bağıl nem değişiminin deneysel incelenmesi. KTÜ Orman Fakültesi, Seminer Serisi 4:125133
Üçüncü K (2000) Bina içi iklim koşullarında odun türü, kalınlık ve enine kesit faktörlerinin bazı ağaç türü odunlarının rutubet değişimi üzerine etkileri. Türk J. Agric. For. 24(3):199-209

Üçüncü K, Aydın A, Tiryaki S (2015) Kapalı mekanda insan faktörü ve odun esaslı malzemelerin havanın bağıl nemine etkisi. Süleyman Demirel Üniversitesi Mühendislik Bilimleri ve Tasarım Dergisi 3 (3):533-540

Üçüncü K, Yılmaz S (1998) Mahal içinde odunun rutubet değişimi ve Türkiye'de odunun mahal içi denge rutubeti miktarının (DRM) dağılımı. Karadeniz Teknik Üniversitesi Araştırma Fonu Başkanlığı. Proje Kod No: 95.113.002.5, Trabzon

Vital BR, Lucia RMD, Lucia RM (1982) Effect of heating on dimensional stability and higrocopicity of wood. Revista Arvore, 6(2):150-161 